\title{
Bio-activation of Inert pHEMA Matrices with Phosphate Loaded Cellulose Fibers in Order to Induce Mineralization
}

\author{
ANDRADA SERAFIMㄴ, MIHAI OCTAVIAN CONSTANTINESCU², FLORINEL TIRDEA IORDACHE², EUGENIU VASILE ${ }^{3}$, \\ ADRIANA LUNGU ${ }^{1,2 *}$, RODICA MARINESCU4*, IZABELA CRISTINA STANCU1,2 \\ ${ }^{1}$ University Politehnica of Bucharest, Advanced Polymer Materials Group, 1-7 Ghe. Polizu Str., 011061, Bucharest, Romania \\ ${ }^{2}$ University Politehnica of Bucharest, Faculty of Medical Engineering, 1-7 Ghe. Polizu Str., 011061, Bucharest, Romania \\ ${ }^{3}$ University Politehnica of Bucharest, Department of Science and Engineering of Oxide Materials and Nanomaterials, 1-7 Ghe. \\ Polizu Str., 011061, Bucharest, Romania \\ ${ }^{4}$ Colentina Clinical Hospital Bucharest, 19-21 Stefan cel Mare Blvd., 72202, Bucharest, Romania
}

Luffa cylindrica fibers were purified through alkaline treatment and loaded with phosphate as mineral precursor. Their capacity of acting as bioactivator for an inert polymer was evaluated. In this respect, the $\mathrm{PO}_{4}^{3-}$ - Luffa fibers were loaded in a polymeric matrix known not to promote biomineralization through immersion in mineralization media. The synthesized materials were subjected to alternative Ca/P baths and the formation of mineral was investigated through SEM. Also, the mechanical properties and the water affinity of the un-mineralized and mineralized materials were investigated.

Keywords: pHEMA, Luffa cylindrica, mineral

The increased number of accidents and diseases that result in bone lost or damage leads to a continuous and increased need for performant bone grafts [1]. The development of such materials has been one of the main research themes for a large number of scientists, and made the subject of an impressive number of scientific papers. A simple search on sciencedirect.com using bone and materials generates almost 500.000 results, of witch over 26.000 were published in 2016 [2]. Even so, the use of iliac crest bone graft remains the golden standard in bone grafting [3] and the development of artificial bone graft represents a remaining challenge. In this respect, several materials have been used, including metals and metal alloys [4 - 7], ceramics [8 - 10] and natural or synthetic polymers [11 - 15]. Recently, composite polymers based on a polymeric matrix and natural fibers seem to get increased attention for such application, due to their capacity to combine the tailorable properties of the synthetic component with the bioactivity of the natural one [16 - 18]. Moreover, hydrogel polymers are particularly appealing due to their water retention ability and implicitly tunable mechanical properties and capacity to generate porous scaffolds that resemble the natural extracellular matrix (ECM) [19].

Poly (2-Hydroxyethyl methacrylate) (pHEMA) is one of the most used polymers for the generation of hydrogels with biomedical applications due to its tunable water affinity, biocompatibility, ease of sterilization and ease of handling [12, 19-21]. Since pHEMA alone is inert to biological processes, in bone tissue engineering itis usually combined with bioactive molecules that are capable to induce the formation of mineral phase $[19,20]$.

In this study, Luffa cylindrica loaded with phosphate as mineral precursor was investigated as a bio-activator for a pHEMA based hydrogel matrix. Luffa is a tropical forest plant from the Cucurbitaceous family [18], which is usually dried and used as an exfoliating bath sponge or inner filler for filters [17]. The dried plant has a particular architecture, resembling a fibrous network formed by bundles of cellulose microfibers glued together by impurities such as

* email: adriana.lungu@upb.ro; rodicamarinescu@ymail.com hemicellulose and lignin [16, 17, 21]. The plants were investigated for various applications, varying from construction material [23] or water treatment [24] to antiinflammatory component [25] or filler in composite materials [17].

The presentstudy presents the synthesis of hybrid natural - synthetic materials based on pHEMA and phosphorus loaded Luffa fibers. The capacity of the $\mathrm{PO}_{4}^{3-}$ Luffa to act as a bio-activator for the pHEMA matrix was investigated by incubating the synthesized materials into alternative $\mathrm{Ca} /$ $P$ baths with the aim of generating the formation of mineral phase. The water affinity of the synthesized materials and their mechanical properties were also investigated.

\section{Experimental part}

Materials and methods

HEMA, pHEMA (both supplied by Sigma-Aldrich) and ethylene glycol (EG) (supplied by Alfa Aesar) were used as such. Ethylene glycol dimethacrylate (EGDMA) was purchased from Fluka and used as cross linker and ammonium persulfate (APS) (Sigma Aldrich) was used as polymerization initiator. Luffa cylindrica was purchased from pharmacies in Romania where it is sold as bath sponge and it was purified prior to use with $\mathrm{NaOH}$ (Sigma Aldrich) aqueous solution. Calcium chloride $\left(\mathrm{CaCl}_{2}\right)$ and sodium phosphate $\left(\mathrm{Na}_{2} \mathrm{HPO}_{4}\right.$ ) (Sigma Aldrich) were used as mineralization precursors.

\section{Luffa fibers preparation}

The commercial Luffa was cut and subsequently grinded in liquid nitrogen until fibers of $1-2 \mathrm{~mm}$ were obtained. The fibers were then purified in an alkaline solution of $\mathrm{NaOH}$ ( $10 \%$ wt/vol.) for $45 \mathrm{~min}$ under vigorous stirring, thoroughly washed with double distilled water $(d d w)$ and dried at $37^{\circ} \mathrm{C}$. In order to be loaded with mineral precursor, the purified fibers were immersed in a solution of $\mathrm{Na}_{2} \mathrm{HPO}_{4}(0.5 \mathrm{M})$ for $6 \mathrm{~h}$, at room temperature (RT).

\section{Synthesis of the reinforced Luffa-hydrogel composite}

The composite materials were obtained through a twostep procedure: (1) firstlya monomer-polymer system was 


\begin{tabular}{|c|c|c|}
\hline \multirow{13}{*}{$T_{i-j}$} & $\begin{array}{c}\text { i - Luffa loading ratio, \% wt } \\
\text { with respect to HEMA }\end{array}$ & $\begin{array}{c}\mathbf{j} \text { - number of } \\
\text { mineralization cycles }\end{array}$ \\
\hline & \multirow{3}{*}{0} & 0 \\
\hline & & 1 \\
\hline & & 3 \\
\hline & \multirow{3}{*}{30} & 0 \\
\hline & & 1 \\
\hline & & 3 \\
\hline & \multirow{3}{*}{40} & 0 \\
\hline & & 1 \\
\hline & & 3 \\
\hline & \multirow{3}{*}{50} & 0 \\
\hline & & 1 \\
\hline & & 3 \\
\hline
\end{tabular}

Table 1

THE COMPOSITIONS OF THE SYNTHESIZED MATERIALS AND CORRESPONDING CODES

obtained using a 1:1 = HEMA: pHEMA (wt) ratio. After the complete dissolution of the polymer in the monomer at room temperature, EGDMA ( $1 \%$ molar ratio with respect to the monomer) and $\mathrm{EG}(35 \% \mathrm{vol}$. ratio with respect to the liquid component of the system) were added. The homogenization of the system was performed by intensive stirring at RT. Subsequently, the polymerization initiator was added. In this respect, an aqueous solution of APS was used, the initiator being added in a ratio of $1 \%$ with respect to the $C=C$ links in the system. The final content of water in the systems was maintained at $10 \%$ (vol.). (2) In the second step of the synthesis, the system obtained as previously described was loaded with phosphate-loaded Luffa fibers. The loading ratios (further denoted $i$ ) of the polymer with Luffa are presented in table 1. The polymerization was performed at $65^{\circ} \mathrm{C}$ for $30 \mathrm{~min}$, followed by a post-polymerization stage of $1 \mathrm{~h}$ at $80^{\circ} \mathrm{C}$. Subsequently, the samples we thoroughly washed with ddw.

\section{Mineralization of the obtained composite scaffolds}

In order to induce the formation of the mineral phase, the synthesized materials were alternatively immersed in $\mathrm{Ca}^{2+} / \mathrm{PO}_{4}^{3-}$ baths, as described in a previously reported study [14]. Briefly, the samples were immersed in $0.5 \mathrm{M} \mathrm{CaCl}$ solution for $30 \mathrm{~min}$, followed by washing with $\mathrm{ddw}$, and then immersed in a $0.3 \mathrm{M} \mathrm{Na}_{2} \mathrm{HPO}_{4}$ solution for the same period of time and washed again with ddw. These four steps amount to one cycle of incubation. The samples were subjected to 1 and respectively 3 cycles of incubation in alternative mineralization baths. For simplicity, the mineralized scaffolds will be further denoted as Ti-j, where j represents the number of incubation cycles, as described in table 1. A GFL 3012 Orbital Shaker device was used for the homogenization of the mineralization media. After the final cycle, the particles were washed with ddw for $2 \mathrm{~h}$, at $25^{\circ} \mathrm{C}$ and subsequently dried.

\section{Structural characterization}

Morphological and microstructural characteristics were investigated by scanning electron microscopy (SEM) using a QUANTA INSPECT $F$ equipped with a field emission gun with $1.2 \mathrm{~nm}$ resolution and a and with an X-ray energy dispersive spectrometer (EDAX). The analyses were performed on gold-sputtered dried samples. Micrographs were registered both on the surface and in the cross-section of the mineralized specimens.

\section{Evaluation of the water uptake capacity}

In order to evaluate the water affinity of the synthesized materials, three samples of each composition were weighted dry $\left(w_{0}\right)$ and immersed in $d d w$ at $37^{\circ} \mathrm{C}$. The samples were removed from the incubation media, blotted and weighted again at pre-established time periods $\left(w_{t}\right)$ The swelling degree (SD, \%) was calculated using equation 1:

$$
S D, \%=\left(\frac{w t-w 0}{w 0}\right) * 100
$$

The equilibrium value is considered the maximum swelling degree (MSD, \%).

\section{Evaluation of the mechanical behaviour}

Evaluation of mechanical properties of final generated material was performed using a CT3 texture analyzer with a 4500 grams cell load (Brookfield Engineering) in compression mode. Cylindrical samples with a diameter of $9.5 \mathrm{~mm}$ and a thickness of $6 \mathrm{~mm}$ were placed on a plate and uniaxial pressed by the mechanical cell. The compression speed was set at $0.5 \mathrm{~mm} / \mathrm{s}$. A stressdeformation curve was plotted and the compression modulus was computed for each composition.

\section{Results and discussions}

\section{Mineralization potential}

SEM characterization reveals non-homogenous materials with randomly dispersed bundles of fibers (average diameter of the bundle $500 \mathrm{~mm}$ ) into the polymer matrix (fig. 1A). The fibers have a parallel distribution and a hollow geometry (average inner diameter $20 \mathrm{~mm}$ ) conferring a longitudinal porosity (fig. $1 \mathrm{~A}, \mathrm{~B}$ ). The incubations in $\mathrm{Ca} / \mathrm{P}$ baths generated randomly dispersed needle-like mineral formations, of nanometric dimensions. The micrographs registered after one cycle of incubation in alternative $\mathrm{Ca} / \mathrm{P}$ baths showed small nanostructured mineral deposits on the surface of the fibrous structures (white arrows in fig. 1C) and at the interface between the cellulose fibers and the pHEMA matrix (fig. 1D). After 3 cycles of incubation in alternative baths, the mineral deposits are more prominent and in a higher amount (fig. $1 E, F)$. EDAX analysis confirmed the formation of apatitelike mineral after the mineralization treatments (fig.2).

\section{Water affinity}

Apart from the morpho-structural investigation, tests regarding the water affinity of the synthesized materials were also conducted. The results showed that all synthetized materials have good stability and that the water affinity degree is highly dependent on the Luffa loading ratio. The morphology of the fibers must also be taken into account, their hollow structure allowing the uptake of a 

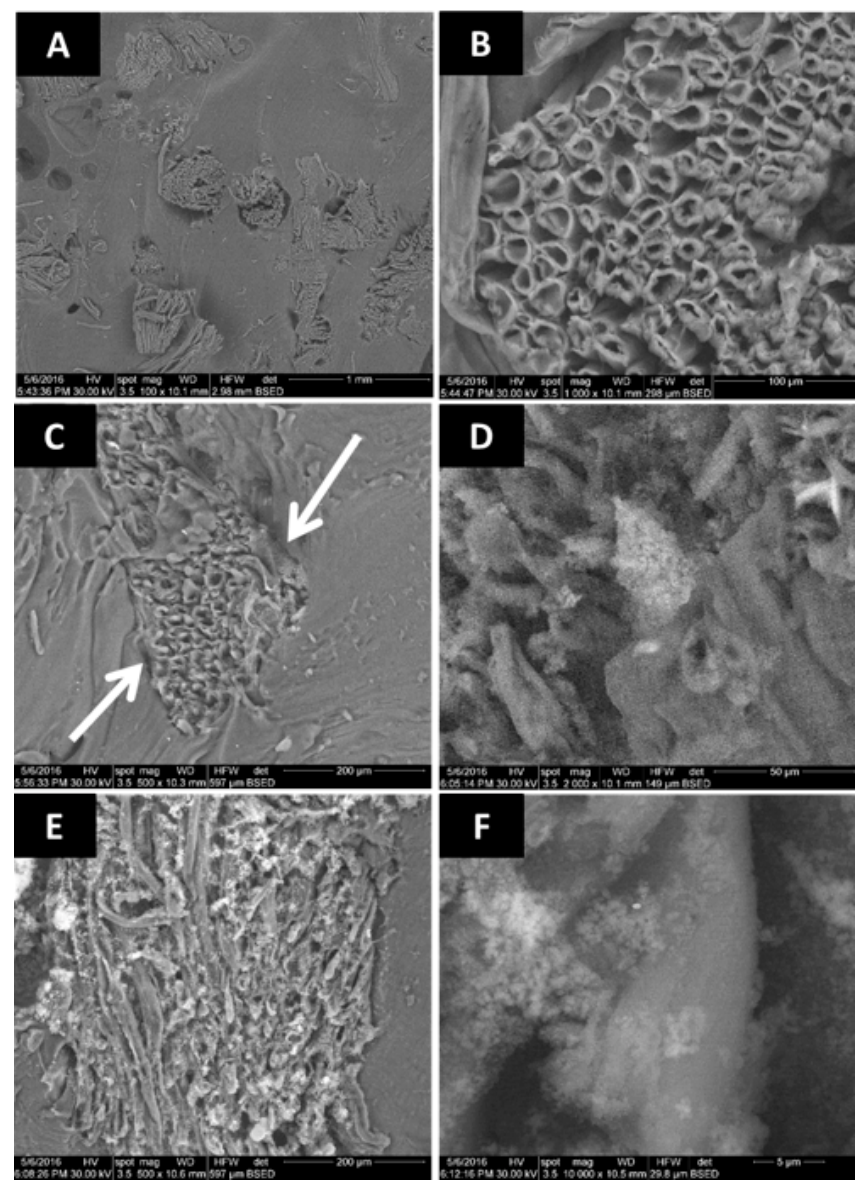

Fig. 1. Micrographs of T50 before mineralization $(A, B)$, after 1 $(C, D)$ and $3(E, F)$ cycles of incubation in $\mathrm{Ca} / \mathrm{P}$ baths. The mineral phase formed after 1 cycle of incubation is indicated using white arrows
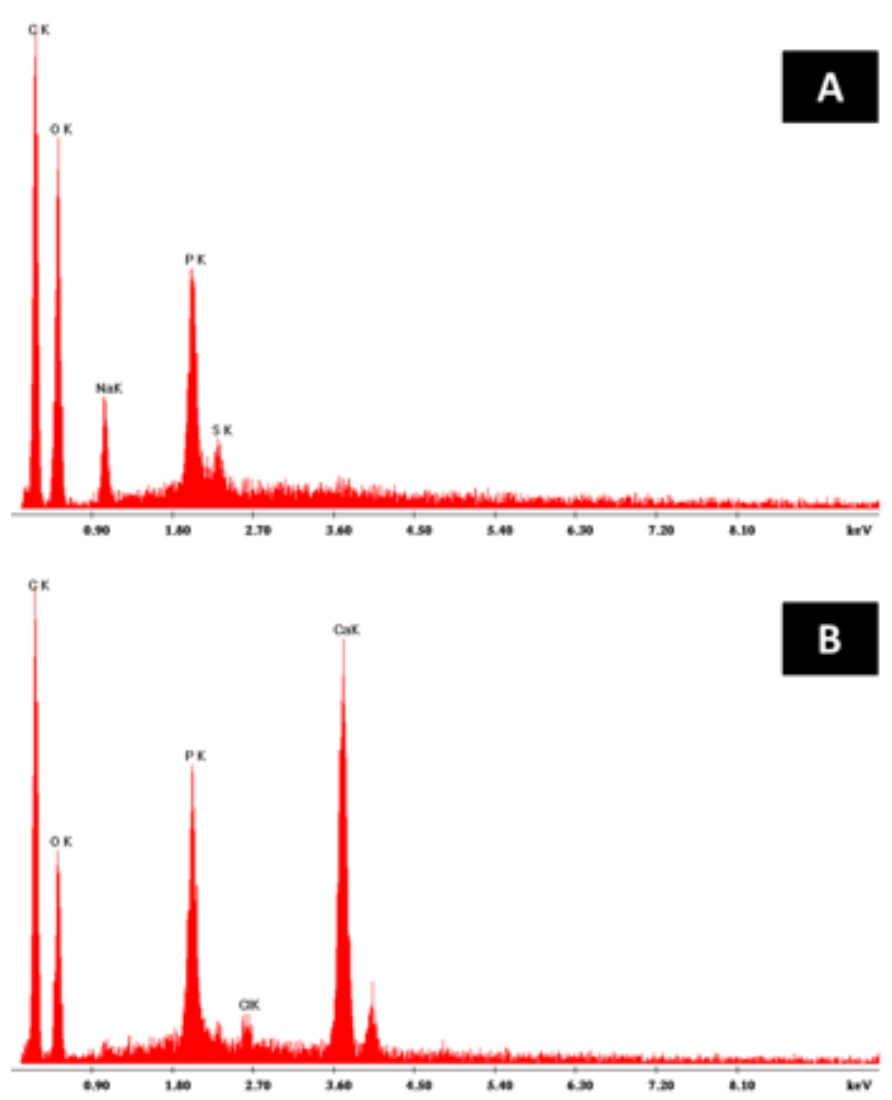

Fig. 2. EDAX spectra, confirming the formation of apatite-like mineral ( $A$ - before the mineralization; $B$ - after three cycles of alternating $\mathrm{Ca} / \mathrm{P}$ baths) larger amount of aqueous solution. As depicted in figure 3 , the maximum swelling degree (MSD) results show that there are no major changes registered between $\mathrm{T}_{30 . \mathrm{j}}$ and $T_{\text {uni, }}$, but an important difference can be observed between $\mathrm{T}^{40-j}$ and $\mathrm{T}_{50 .}$ amounting to a 1.5x increase of the MSD when adding $50 \%$ (wt) Luffa. Also, it can be stated that the formation of mineral leads to a slight decrease of the MSD as it can be noticed, for example, for samples $\mathrm{T}_{30}$ (76 \pm $5.7 \%$ for $\mathrm{T}_{30-\mathrm{f}}$ to $63 \pm 4 \%$ for $\left.\mathrm{T}_{30-3}\right)$ and $\mathrm{T}_{50 . \mathrm{j}}(93 \pm 1.7 \%$ to 87 $\pm 2.3 \%$ for $^{30-2}{ }_{50-3}$ ).
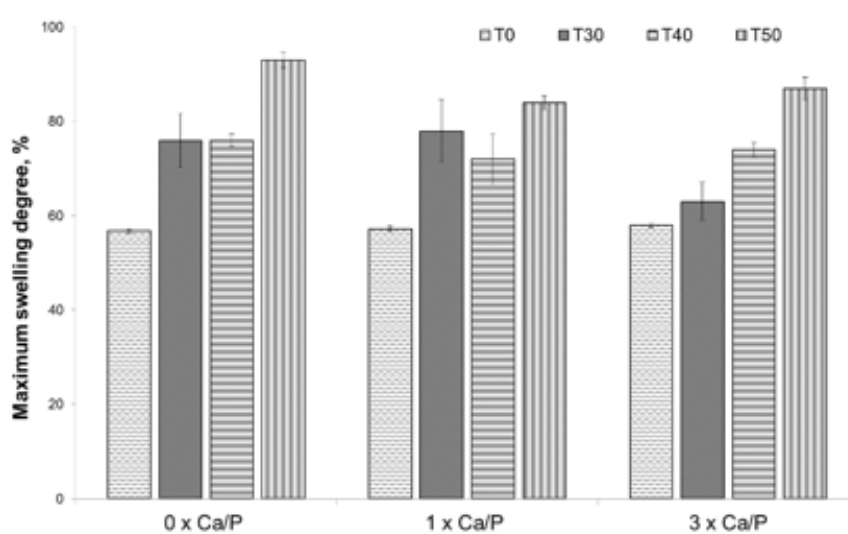

Fig. 3. The influence of the composition and mineralization on the water affinity of the composite Luffa-pHEMA materials and control sample before $(0 \times \mathrm{Ca} / \mathrm{P})$ and after $1(1 \times \mathrm{Ca} / \mathrm{P})$ and respectively $3(3 \times \mathrm{Ca} / \mathrm{P})$ cycles of mineralization

\section{Mechanical properties}

With regards to the mechanical properties of the materials, compression tests were performed on the fully hydrated samples, showing that the materials with a higher content of Luffa fibers have a lower compression modulus, which equals a higher elasticity. The results obtained on the compression tests are in agreement with the data registered in the water affinity tests, stating for the plasticizer effect of the hydrated hollow Luffa fibers as proven by the decrease of the compression modulus from $1.95 \pm 0.06 \mathrm{kPa}$ for $\mathrm{T}_{0-0}$ to $0.4 \pm 0.19 \mathrm{kPa}$ for $\mathrm{T}_{50.0^{\circ}}$. The effect is maintained also for the mineralized scaffolds. The elasticity increases with the increase of the swelling degree, as depicted in figure 4.

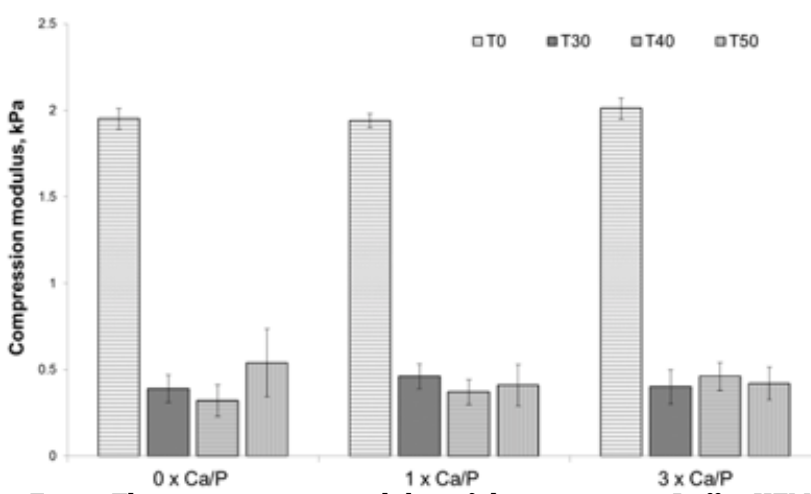

Fig. 4. The compression modulus of the composite Luffa-pHEMA materials and control sample before and after 1 and respectively 3 cycles of mineralization

\section{Conclusions}

The present study confirmed the capacity of the Luffa fibers loaded with mineral precursors to act as a mineralization bioactivator for an inert polymer matrix.

The preincubation of the cellulosic fibers in a phosphate solution directly induced the development of nanostructured mineral phase, even after only one mineralization cycle. As it was expected, increasing the 
number of mineralization cycles leads to a stronger mineralization.

The water affinity of the materials is directly dependent with the: Luffa ratio. As it has been shown in the previous results, the highest result for the water affinity is registered for the scaffolds with $50 \%$ (wt) Luffa fibers in respect to the HEMA monomer.

The results obtained for the mechanic tests are in agreement with the water affinity results. The value of the compression modulus for the composite materials is significantly lower than for the synthesized polymeric system, but there are no significant differences between the composite materials with various Luffa loadings.

Considering the envisaged destination of these materials - bone tissue engineering - future work should regard the investigation of bio-interactions with relevant cells and simulated physiologic fluids. Also, the optimization of the materials' homogeneity must be considered.

Acknowledgement: This work is supported by a grant of the Romanian National Authority for Scientific Research and Innovation, CNCS UEFISCDI, project number PN-II-RU-TE-2014-4-1423.

\section{References}

1.ZADEGAN S., HOSAINALIPOUR M., REZAIE H. R., GHASSAI H., SHOKRGOZAR M. A., Mater. Sci. Eng. C, vol. 31, no. 5, pp. 954-961, 2011.

2.***http://www.sciencedirect.com/science? ob=ArticleListURL\& method $=$ list\&_ArticleListID $=-1075067749 \&$ sort $=r \&$ \&st $=13 \&$ view

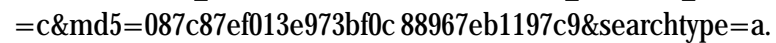

3.SEN M. K., T. MICLAU, Injury, vol. 38, no. 1, pp. S75-S80, 2007.

4.ZHANG E., YANG L., XU J., CHEN H., Acta Biomater., vol. 6, no. 5, pp. $1756-1762,2010$.

5.WINDHAGEN H., RADTKE K., WEIZBAUER A., DIEKMANN J., NOLL Y., KREIMEYER U., SCHAVAN R., STUKENBORG-COLSMAN C., WAIZY H., Biomed. Eng. Online, vol. 12, no. 1, p. 62, 2013.

6.STAIGER M. P., PIETAK A. M., HUADMAI J., DIAS G., Biomaterials, vol. 27, no. 9, pp. 1728-1734, 2006.

7.LIU X., CHU P. K., DING C., Mater. Sci. Eng. R Reports, vol. 47, no. 3, pp. 49-121, 2004.

8.GRYSHKOV O., KLYUI N. I., TEMCHENKO V. P., KYSELOV V. S., CHATTERJ EE A., BELYAEV A. E., LAUTERBOECK L., IARMOLENKO D., GLASMACHER B., Mater. Sci. Eng. C, vol. 68, pp. 143-152, 2016.
9.KOH I., GOMBERT Y., PERSSON C., ENGQVIST H., HELGASON B., FERGUSON S. J., J. Mech. Behav. Biomed. Mater., vol. 61, pp. 519-529, Aug. 2016.

10.MALMSTROM J ., ANDERUD J ., ABRAHAMSSON P., WALIVAARA D.A., ISAKSSON S. G., ADOLFSSON E., Int. J. Oral Maxillofac. Surg., vol. 45, no. 10, pp. 1246-1252, Oct. 2016.

11.CECOLTAN S., PETRE D. G., STAN E. G., VASILE E., CIOFLAN H. E., ISTODORESCU M., CRISTESCU I., MARINESCU R., LAPTOIU D., STANCU I. C., Key Eng. Mater., vol. 638, pp. 20-26, 2015.

12.MABILLEAU G., STANCU I. C., HONORE T., LEGEAY G., CINCU C., BASLE M. F., CHAPPARD D., J. Biomed. Mater. Res. A, vol. 77, no. 1, pp. 35-42, Apr. 2006.

13.PETRE D. G., SERAFIM A., LUNGU A., VASILE E., CRISTESCU I., ISTODORESCU M., Key Eng. Mater., vol. 614, pp. 26-30, 2014.

14.PETRE, D., CECOLTAN, S., SERAFIM, A., LUNGU, A., DRAGUSIN, D. M., STAN, E. G., TUCUREANU, C., VASILE, E., SALAGEANU, A., ISTODORESCU, M., IOVU, H., STANCU, I. C., Mat. Plast., 53, no. 2, 2016, p. 269

15.HOLLINGER J. O., LEONG K., Biomaterials, vol. 17, no. 2, pp. 187194, Jan. 1996.

16.SIQUEIRA G., BRAS J., FOLLAIN N., BELBEKHOUCHE S., MARAIS S., DUFRESNE A., Carbohydr. Polym., vol. 91, no. 2, pp. 711-717, Jan. 2013.

17.KOCAK D., MISTIK S. I., AKALIN M., Biofiber Reinforcements in Composite Materials, Istambul, 2015, pp. 689-699.

18.PARIDA C., DAS S. C., DASH S. K., Procedia Chem., vol. 4, pp. 53-59, 2012.

19.SONG J., SAIZ E., BERTOZZI C. R., J. Eur. Ceram. Soc., vol. 23, no. 15, pp. 2905-2919, 2003.

20.HUANG J ., ZHAO D., DANGARIA S. J ., LUAN X., DIEKWISCH T. G. H., JIANG G., SAIZ E., LIU G., TOMSIA A. P., Polymer (Guildf)., vol. 54, no. 2, pp. 909-919, 2013.

21.CRETAN, M., GRIGORAS, S., HANGANU, L., STAMATE, C., HANGANU, S. C., Mat. Plast., 45, no.1, 2008, p. 109

22.J. SHEN, Y. MIN XIE, X. HUANG, S. ZHOU, D. RUAN, J. Mech. Behav. Biomed. Mater., vol. 15, pp. 141-152, 2012.

23.TONG Y., ZHAO S., MA J ., WANG L., ZHANG Y., GAO Y., XIE Y. M., Constr. Build. Mater., vol. 71, pp. 327-333, 2014.

24. MALLAMPATI R., TAN K. S., VALIYAVEETTIL S., Int. Biodeterior. Biodegradation, vol. 103, pp. 8-15, 2015.

25.CHOU L.-H., LIU H.-L., KAO T.-H., J. Funct. Foods, vol. 27, pp. 150159, 2016.

Manuscript received: 16.12 .2016 